\title{
IMPLEMENTASI "HASUPA HASUNDAU” DALAM MEMBINA PESERTA DIDIK
}

\author{
Ahyanati Fitri*, Teti Berliani, Reddy Siram \\ Universitas Palangka Raya \\ E-mail: ahyanatifitri18@gmail.com
}

\begin{abstract}
Abstrak: Penelitian ini bertujuan untuk mendeskripsikan tentang Implementasi Hasupa Hasundau dalam Membina Peserta Didik di SDN 5 Menteng Palangka Raya, diilihat dari aspek: (1) Proses terbentuknya program Hasupa Hasundau dalam membina peserta didik, (2) Mekanisme program Hasupa Hasundau dalam membina peserta didik, dan (3) Faktor pendukung dan kendala yang dihadapi dalam pelaksanaan program Hasupa Hasundau. Penelitian ini menggunakan pendekatan kualitatif dengan rancangan studi kasus. Teknik pengumpulan data dilakukan dengan cara: observasi, wawancara dan dokumentasi. Pengabsahan data dalam penelitian ini menggunakan teknik kredibilitas (triangulasi dan pengecekkan anggota) dan konfirmabilitas. Hasil penelitian menunjukkan bahwa: (1) Proses terbentuknya Hasupa Hasundau di SDN 5 Menteng berawal dari adanya program dari Kemendikbud yaitu program kemitraan dan SDN 5 Menteng Palangka Raya menerapkan program kemitraan, pelaksanaannya dilaksanakan pada sebuah wadah yang diberi nama Hasupa Hasundau yang mana kegiatannya adalah melaksanakan pertemuan antara pihak sekolah dengan orang tua siswa, (2) Mekanisme program dilakukan 2 kali pertemuan per semester, mengundang orang tua siswa melalui melalui grup pada WA atau surat, diadakan diskusi untuk menyampaikan pendapat ataupun kebutuhan yang diperlukan anak di sekolah, dan (3) Faktor Pendukung dan Kendala yang dihadapi pada Pelaksanaan Hasupa Hasundau dalam Membina Peserta Didik, yaitu: a) Faktor pendukung adanya keterbukaan atau kepercayaan orang tua terhadap sekolah begitu sebaliknya dalam mendidik anak, kesamaan pola asuh, dan b) Kendala berasal ada beberapa orang tua yang berhalangan hadir karena masalah waktu, seperti orang tua yang sibuk bekerja.
\end{abstract}

Kata Kunci: Implementasi, Hasupa Hasundau, Peserta Didik, SDN 5 Menteng Palangka Raya

Abstract: This study aims to describe the implementation of Hasupa Hasundau in fostering students at SDN 5 Menteng Palangka Raya, seen from the aspects of: (1) the process of the Hasupa Hasundau program in fostering students, (2) the mechanism of the Hasupa Hasundau program in fostering students, and from aspects: (3) Supporting factors and obstacles encountered in the implementation of the Hasupa Hasundau program. This study used a qualitative approach with case study design. Data collection techniques carried out by: observation, interview and documentation. Validation of data in this study uses the technique of credibility (triangulation and checking members) and confirmability. The results showed that: (1) The process of the formation of Hasupa Hasundau at SDN 5 Menteng began with a program from the Ministry of Education and Culture which is a partnership program and SDN 5 Menteng Palangka Raya implemented a partnership program, the implementation was carried out in a container that was named Hasupa Hasundau where the activity was to carry out a meeting between the school and parents of students, (2) The mechanism of the program is held 2 meetings per semester, inviting parents through groups in WA or letters, holding discussions to express opinions or needs needed by children in school, and (3) Supporting Factors and Constraints faced in the Implementation of Hasupa Hasundau in Fostering Students, namely: a) Supporting factors for parents' openness or trust in school and vice versa in educating children, parity in parenting, and b) Constraints originating there are some parents who are unable to attend attend because of time problems, like parents y I'm busy working.

Keywords: Implementation, Hasupa Hasundau, Students, SDN 5 Menteng Palangka Raya.

\section{PENDAHULUAN}

Pendidikan merupakan tolak ukur kemajuan peradaban suatu bangsa. Kemajuan bangsa dapat terlihat dari pencapaian aspek pembangunan pendidikan yang sesuai dengan tujuan pendidikan dengan implementasinya.
Pendidikan lahir seiring dengan keberadaan manusia bahkan dalam proses pembentukan masyarakat, pendidikan ikut andil untuk menyumbangkan prosesproses perwujudkan pilar-pilar penyangga masyarakat. Peran serta masyarakat dan program peningkatan mutu sekolah 
merupakan dua hal yang tak dapat dipisahkan untuk meningkatkan mutu pendidikan.

Masyarakat memiliki hak memperoleh pendidikan dan kewajiban dalam menjaga keberlangsungan penyelenggaraan proses pendidikan, sebagaimana diamanatkan oleh Undang Undang Sistem Pendidikan Nasional Nomor 20 Tahun 2003 Pasal 7 yang didalamnya memuat bahwasannya: (1) Orang tua berhak berperan serta dalam memilih satuan pendidikan dan memperoleh informasi tentang perkembangan anaknya, dan (2) Orang tua dari anak usia wajib belajar, berkewajiban memberikan pendidikan dasar kepada anaknya.

Banyak hal yang bisa dilakukan oleh masyarakat untuk membantu penyelenggaran pendidikan yang berkualitas, mulai dari menggunakan pelayanan yang tersedia di sekolah sampai keikutsertaannya dalam pengambilan keputusan, pemberian kritik dan saran yang bermanfaat kedepannya. Peran serta masyarakat yang dimaksud untuk peningkatan mutu sekolah mencakup seluruh stakeholder seperti orang tua, masyarakat, komite sekolah dan pihak yang berkaitan.

Untuk meningkatkan mutu layanan pendidikan pada jenjang pendidikan dasar dan menengah melalui Direktorat Pembinaan Sekolah Dasar di bawah naungan Direktorat Jenderal Pendidikan Dasar dan Menengah (Ditjen Dikdasmen) menyelenggarakan fungsi yang berkaitan dengan pelibatan orang tua pada penyelenggaran pendidikan anak di sekolah. Menteri Pendidikan dan Kebudayaan, Muhadjir Effendy memandang perlu dilakukan revitalisasi tugas Komite Sekolah berdasarkan prinsip gotong royong yang melibatkan orang tua siswa untuk ikut serta dalam penyelenggaraan pendidikan anaknya di sekolah, sehingga output yang dihasilkan dari kegiatan komite tersebut dapat meningkatkan mutu pendidikan. Dengan pertimbangan tersebut, pada tanggal 30 Desember 2016, Menteri Pendidikan dan Kebudayaan menandatangani Peraturan Menteri Pendidikan dan Kebudayaan (Permendikbud) Nomor: 75 Tahun 2016 tentang Komite Sekolah.

Dalam peraturan ini disebutkan, bahwa Komite Sekolah adalah lembaga mandiri yang beranggotakan orangtua/wali peserta didik, komunitas sekolah, serta tokoh masyarakat yang peduli pendidikan. Adapun poin kegiatan yang dijabarkan pada Peraturan Menteri Pendidikan dan Kebudayaan (Permendikbud) Nomor: 75 Tahun 2016 tentang Komite Sekolah, yaitu: (1) Memberikan pertimbangan, Menggalang dana dan sumber daya lainnya, (3) Mengawasi pelayanan pendidikan dan, (4) Menindak lanjuti keluhan, saran dan kritik.

Adanya partisipasi orang tua dalam forum atau organisasi yang dibentuk oleh pihak sekolah dan orang tua dapat menjadi alternatif yang sangat bagus membangun komunikasi yang baik antara pihak sekolah dengan orang tua siswa. Dengan adanya kerja sama yang terjalin akan menekan terjadinya kesenjangan yang tidak diinginkan sehingga menghambat peningkatan mutu pendidikan di sekolah. Forum yang dibentuk melalui kegiatan yang melibatkan orang tua juga diharapkan dapat memberikan sumbangsih, kritik serta saran yang dapat dijadikan untuk membangun ekosistem pendidikan yang baik, sehingga dapat menumbuhkan karakter dan budaya prestasi pada peserta didik.

Berkaitan dengan permasalahan di atas, penelitian ini dilakukan di Sekolah Dasar Negeri 5 Menteng Palangka Raya, karena sekolah tersebut sebagai salah satu Sekolah Dasar yang menerapkan program kerja sama yang melibatkan orang tua siswa sebagai objek yang melakukan kemitraan atau kerja sama. Program kemitraan atau kerja sama pada Sekolah Dasar Negeri 5 Menteng Palangka Raya 
dilaksanakan sejak tahun 2016 hingga sekarang.

Mekanisme program kegiatan di Hasupa Hasundau yaitu mengundang orang tua siswa untuk mengadakan pertemuan melalui grup WhatsApp panguyuban bersama orang tua yang dibentuk dengan adanya kesepakatan dengan orang tua siswa. Dalam kegiatan tersebut adanya kegiatan diskusi antara pihak sekolah dengan orang tua membahas mengenai kebutuhan yang dibutuhkan oleh anak di sekolah. Selain itu juga, orang tua dapat menyampaikan keluhan apapun terkait dengan perkembangan yang dihadapi oleh anak, sehingga pertemuan di hasupa hasundau tersebut pihak sekolah terutama kepala sekolah, guru dan orang tua siswa, bersama-sama menyampaikan kritik serta saran yang membangun untuk menemukan solusi yang dihadapi oleh anak. Kegiatan ini juga diharapkan adanya kesamaan pola asuh antara guru dan orang tua dalam mendidik anak. Hal tersebut dibuktikan dengan adanya pemberian materi tentang pendidikan keluarga. Penerapannya guru ataupun orang tua siswa dapat mengaplikasikan materi yang sudah diperoleh untuk diterapkan dalam mendidik anak baik di sekolah atau di rumah.

Hasil dari pelaksanaan program pertemuan antara pihak dengan orang tua siswa melakukan kerja sama dalam upaya membina karakter peserta didik memberi dampak yang positif bagi sekolah yang terlihat dari adanya saran, kritik serta sumbangsih yang diberikan oleh kedua pihak yang melakukan kerja sama. Begitupun dengan keberhasilan pembinaan karakter peserta didik melalui kegiatan pertemuan pihak sekolah dan orang tua di hasupa hasundau anak mendapatkan perhatian dari sekolah dan orang tua yang selalu memantau perkembangannya, mendukung lingkungan belajar yang dapat mengembangakan potensi anak secara utuh. Anak diarahkan untuk menjadi pribadi yang mandiri dan punya karakter melalui pendidikan anak di rumah dan di sekolah.

\section{METODE}

Penelitian ini menggunakan pendekatan kualitatif karena peneliti bermaksud mengungkap realitas yang terjadi dengan cara memahami fenomenafenomena yang ada di lapangan dan mengkaji secara lebih mendalam pada kondisi yang alamiah tentang informasiinformasi mengenai Implementasi Hasupa Hasundau dalam Membina Peserta Didik di Sekolah Dasar Negeri 5 Menteng Palangka Raya. Peneliti menerapkan pendekatan kualitatif ini berdasarkan beberapa pertimbangan yaitu dengan memanfaatkan kondisi lapangan yang alamiah sangat bermanfaat bagi peneliti untuk menemukan fakta serta makna dari Implementasi Hasupa Hasundau dalam Membina Peserta Didik. Instrument atau alat pengumpulan data dalam penelitian kualitatif adalah peneliti itu sendiri sebagai instrument kunci. Penelitian ini dilakukan di Sekolah Dasar Negeri 5 Menteng Palangka Raya. Adapun pada penelitian ini menggunakan rancangan studi kasus, karena peneliti melakukan penelitian dengan menggunakan satu lembaga pendidikan sebagai kasus yang akan diteliti.

Prosedur yang digunakan oleh peneliti dalam penelitian ini adalah menggunakan observasi, wawancara, dan dokumentasi. Analisis data yang digunakan dalam penelitian ini adalah analisis data model interaktif (interactive model) menurut Miles and Huberman (dalam Sugiyono 2015:338) terdiri dari tiga alur kegiatan yang terjadi secara bersamaan, yaitu: (1) reduksi data, (2) penyajian data, dan (3) penarikan kesimpulan/verifikasi. Dalam penelitian ini, peneliti hanya menggunakan dua dari empat kriteria dalam melakukan pengecekan keabsahan data. Adapun kriteria tersebut adalah 1) Kredibilitas, 2) Konfirmabilitas. 


\section{HASIL DAN PEMBAHASAN}

Hasil

\section{Proses Terbentuknya Program Hasupa Hasundau dalam Membina Peserta Didik}

Adapun proses terbentuknya Hasupa Hasundau di SDN 5 Menteng yaitu: (a) Berawal dari adanya program dari Kemendikbud yaitu program kemitraan pada tahun 2015, (b) SDN 5 Menteng Palangka Raya menerapkan program kemitraan keluarga dilaksanakan di sebuah wadah yang bernama Hasupa Hasundau, dan (c) Kegiatannya adalah melaksanakan pertemuan antara pihak sekolah dengan orang tua siswa. Melakukan diskusi atau hal-hal penting yang berkaitan dengan kebutuhan sekolah atau kebutuhan siswa.

\section{Mekanisme Hasupa Hasundau dalam Membina Peserta Didik}

Adapun mekanise Hasupa

Hasundau di SDN 5 Menteng yaitu: (a) Program dilaksanakan mengikuti petunjuk dari program Kemendikbud dilakukan 2 kali pertemuan per semester, yaitu dilaksanakan pada awal semester dan pertengahan semester, (b) Mengundang orang tua siswa melalui informasi yang disebar melalui grup panguyuban orang tua pada WA atau surat, (c) Diadakan diskusi antara pihak sekolah dengan orang tua siswa untuk menyampaikan pendapat ataupun kebutuhan yang diperlukan anak di sekolah, permasalahan yang dihadapi anak, pola asuh, dan (d) Pihak sekolah melakukan pendidikan keluarga dengan cara memberikan materi kepada orang tua siswa yang dapat bermanfaat untuk mendidik anak.

\section{Faktor Pendukung dan Kendala yang Dihadapi pada Pelaksanaan Program Hasupa Hasundau dalam Membina Peserta Didik.}

Faktor Pendukung, meliputi: (a) Faktor pendukung kegiatan pertemuan antara pihak sekolah yang melibatkan orang tua siswa untuk kerja sama sehingga memberikan teladan dan menumbuhkan karakter peserta didik, (b) Adanya keterbukaan atau kepercayaan orang tua terhadap sekolah begitu sebaliknya dalam mendidik anak, kesamaan pola asuh, dan (c) Guru dan orang tua menjadi pro aktif dalam menyampaikan pendapat dan memantau perkembangan anaknya di sekolah atau di rumah. Faktor Kendala, meliputi: (a) Masih terdapat sebagian kecil orang tua yang kurang perduli akan pentingnya kegiatan pertemuan di Hasupa Hasundau, sehingga orang tua tidak mengetahui mengenai perkembangan anaknya di sekolah, dan (b) Pada saat pelaksanaan pertemuan ada beberapa orang tua yang berhalangan hadir karena masalah waktu, seperti orang tua yang sibuk bekerja.

\section{Pembahasan}

Hasil penelitian berkenaan dengan proses terbentuknya Hasupa Hasundau di SDN 5 Menteng yakni berawal dari adanya program Kemitraan yang dicanangkan oleh Kementerian Pendidikan dan Kebudayaan pada tahun 2015; yang kemudian diterapkan dalam lingkup sekolah sebagai lembaga pendidikan formal dengan mengangkat unsur kearifan lokal daerah yang diberi nama Hasupa Hasundau. Hasupa Hasundau merupakan wadah menampung aspirasi, pendapat, masukan, kritikan dan saran dari para orang tua siswa di sekolah. Dalam program Hasupa Hasundau, pihak sekolah dan para orang tua melakukan focus group discussion (FGD) yang berkaitan dengan hal-hal penting terkait kebutuhan siswa di sekolah. Proses pelibatan orang tua di sekolah memiliki dampak yang sangat positif dalam mendukung kemajuan sekolah. Sekolah sebagai salah satu elemen penting di tengah-tengah masyarakat sangatlah memerlukan dukungan dan partisipasi penuh dari masyarakat dalam rangka kelancaran proses pendidikan. Untuk mendapatkan produktivitas sekolah yang bermutu serta pencapaian tujuan sekolah 
secara optimal, maka sekolah harus memanage keseluruhan substansi terkait dalam proses pendidikan dan pembelajaran yang ada di sekolah, salah satunya manajemen hubungan masyarakat (humas).

Hasil penelitian itu sejalan dengan pendapat Gorton yang dikutip Rodliyah (dalam Wahyuni, 2015) menegaskan bahwa sekolah itu tidaklah berdiri sendiri atau sungguh terpisah kegiatannya dari konteks sosial. Untuk mendorong partisipasi masyarakat yang aktif, sekolah diharapkan dapat melakukan hubungan kerjasama yang baik dengan masyarakat, salah satunya melalui perencanaan, pengambilan keputusan dan pengembangan sekolah yang melibatkan keseluruhan stakeholders sekolah dan disesuaikan pula dengan tuntutan kemajuan zaman pada masa sekarang; terutama partisipasi masyarakat untuk terlibat langsung dalam proses pengambilan keputusan di sekolah. Pelibatan orang tua siswa di sekolah dimulai dari proses merencanakan, melaksanakan, mengawasi dan mengevaluasi setiap program yang ada di sekolah. Hal ini dilakukan agar setiap program yang ada di sekolah dapat sesuai dengan tuntutan kebutuhan di masyarakat dan berdampak pada pengembangan sekolah untuk menjadi lebih baik. Hal itu sejalan dengan Wahyuni (2015) yang mengungkapkan bahwa pelibatan masyarakat dalam menentukan arah dan kebutuhan harus sesuai dengan konteks masyarakat itu sendiri, serta perumusan program-program yang melibatkan masyarakat pada seluruh proses dan aktivitas penyelenggaraan pendidikan, sejak dari tahapan perencanaan, pelaksanaan, penilaian, sampai pada pendayagunaan lulusan dalam upaya pengembangan individu anak didik dan pengembangan masyarakat. Intinya, orang tua dan pihak sekolah harus saling bekerjasama dan berkoordinasi sebagai wujud dari tanggungjawab terhadap kemajuan dan pengembangan sekolah ke depannya. Sejalan dengan itu, Pidarta (2011), bahwa sekolah sebagai sistem yang terbuka, yang selalu mengadakan kerjasama dengan warga masyarakat lainnya, secara bersama-sama membangun dibidang pendidikan. Lebih lanjut, Burhanuddin et al (2003) mengatakan masyarakat perlu membantu penyelenggaraan pendidikan agar kualitas pertumbuhan dan perkembangan pendidikan dapat dipacu secara cepat, akhirnya kualitas kehidupan masyarakat dapat meningkat. Hasil temuan penelitian yang dilakukan oleh Manap (2013) bahwa dalam prosesnya, pendidikan harus mendapat dukungan dari berbagai pihak terkait, terutama dari masyarakat pendukungnya, sebab pendidikan di sekolah diadakan merupakan perwujudan dari pemenuhan atas kebutuhan masyarakat untuk menciptakan agar anakanak mereka menjadi lebih berbudaya ketika mereka keluar dari sistem pendidikan persekolahan, dan budaya masyarakat pada masa yang akan datang menjadi lebih baik dibandingkan dengan kondisi masa lalu dan kini.

Hasil penelitian yang berkenaan dengan mekanise Hasupa Hasundau di SDN 5 Menteng menunjukkan bahwa: 1) program Hasupa Hasundau dilaksanakan 2 kali dalam tiap semester, yaitu dilaksanakan pada awal semester dan pertengahan semester; 2) program Hasupa Hasundau mengundang orang tua siswa melalui informasi yang disebar lewat grup panguyuban orang tua pada WA atau pengiriman surat secara resmi; 3) dalam program Hasupa Hasundau diadakan diskusi antara pihak sekolah dengan orang tua siswa untuk menyampaikan pendapat ataupun kebutuhan yang diperlukan anak di sekolah, permasalahan yang dihadapi anak, pola asuh; serta 4) pihak sekolah melakukan pendidikan keluarga dengan cara memberikan materi kepada orang tua siswa yang dapat bermanfaat untuk mendidik anak.

Hasil penelitian tersebut sesuai dengan petunjuk teknis dari Kemitraan 
Sekolah Dasar dengan Keluarga dan Masyarakat (2016) menyatakan bahwa "Wali kelas berperan penting dalam menjalin kemitraan dengan orang tua/wali murid. Pertemuan wali kelas dengan orang tua/wali murid dilaksanakan minimal 2 kali per semester atau 4 kali dalam 1 tahun ajaran, yakni : (1) pada hari pertama masuk sekolah di bulan Juli; (2) menjelang ujian tengah semester 1 di bulan September; (3) Menjelang ujian tengah semester 2 di bulan Maret; dan (4) setelah ujian akhir semester di bulan Juni”. Sementara itu, Keith dan Girling (1991) yang mengatakan tingginya pelibatan orang tua di sekolah memberikan manfaat yang sangat besar bagi pengelolaan pendidikan yaitu terutama berupa tambahan sumber daya, dukungan politik, kesempatan untuk motivasi dan pengembangan profesi, serta meningkatnya prestasi murid. Lebih lanjut, Usman (2013) mengatakan usaha dalam melibatkan masyarakat memiliki manfaat: (1) dapat menghasilkan keputusan yang baik dan perbaikan yang lebih efektif karena mencakup pandangan dan pemikiran dari pihak yang langsung berhubungan dengan situasi kerja, (2) meningkatkan "rasa memiliki" dan tanggungjawab atas keputusan dengan melibatkan orang yang harus melaksanakan. Untuk meningkatkan intensitas dan ekstensitas hubungan sekolah dan masyarakat, maka diperlukan kreativitas, inovasi, dan keaktifan seluruh warga sekolah terutama kepala sekolah dalam menjalin komunikasi dengan pihak masyarakat. Sejalan dengan itu, Suharto (2012) juga mengatakan orang tua, para pemimpin masyarakat, administrator, anggota dewan sekolah, dan para warga merupakan bagian integral di dalam upaya pengembangan, produksi, implementasi, dan penilaian dari pendidikan yang berbasis pada masyarakat.

Hasil penelitian yang berkenaan dengan 1) Faktor Pendukung Implementasi Hasupa Hasundau: a) Faktor pendukung kegiatan pertemuan antara pihak sekolah yang melibatkan orang tua siswa untuk kerja sama sehingga memberikan teladan dan menumbuhkan karakter peserta didik; b) Adanya keterbukaan atau kepercayaan orang tua terhadap sekolah begitu sebaliknya dalam mendidik anak, kesamaan pola asuh; serta c) Guru dan orang tua menjadi pro-aktif dalam menyampaikan pendapat dan memantau perkembangan anaknya di sekolah atau di rumah. 2 ) Kendala dalam Implementasi Hasupa Hasundau: a) Masih terdapat beberapa orang tua yang kurang perduli akan pentingnya kegiatan pertemuan di Hasupa Hasundau, sehingga orang tua tidak mengetahui mengenai perkembangan anaknya di sekolah; b) pada saat pelaksanaan pertemuan ada beberapa orang tua yang berhalangan hadir karena masalah waktu, seperti orang tua yang sibuk bekerja.

Sejalan dengan itu, Komariah \& Triatna (2008) mengungkapkan masyarakat merupakan mitra untuk mengembangkan sekolah, sekolah tidak dapat maju pesat tanpa bantuan dari masyarakat. Oleh karena itu, kemitraan dengan masyarakat harus terus terjalin. Lebih lanjut, Mulyasa (2012) mengatakan kepala sekolah yang baik merupakan salah satu kunci untuk bisa menciptakan hubungan yang baik antara sekolah dan masyarakat secara efektif karena harus menaruh perhatian tentang apa yang terjadi pada peserta didik di sekolah dan apa yang dipikirkan orang tua tentang sekolah. Melalui hubungan yang harmonis, diharapkan tercapai tujuan hubungan sekolah dengan masyarakat,yaitu terlaksananya proses pendidikan di sekolah secara produktif, efektif, dan efisien sehingga menghasilkan lulusan sekolah yang produktif dan berkualitas. Sementara itu, Depdiknas (2002) menegaskan bahwa esensi hubungan sekolah dan masyarakat adalah untuk meningkatkan keterlibatan, kepedulian, kepemilikan, dan dukungan dari masyarakat terutama dukungan moral dan finansial. 


\section{SIMPULAN}

Berdasarkan hasil penelitian dan pembahasan yang telah diuraikan sebelumnya, dapat dirumuskan kesimpulan sebagai berikut:

1. Proses terbentuknya Hasupa Hasundau di SDN 5 Menteng berawal dari adanya program dari Kemendikbud yaitu program kemitraan pada tahun 2015 dan SDN 5 Menteng Palangka Raya menerapkan program kemitraan keluarga, yang mana kegiatannya dilaksanakan pada suatu wadah yang diberi nama Hasupa Hasundau. Kegiatannya adalah melaksanakan pertemuan untuk menjalin kerja sama antara pihak sekolah dengan orang tua siswa untuk melakukan diskusi atau hal-hal penting yang berkaitan dengan kebutuhan sekolah atau kebutuhan siswa.

2. Mekanisme Hasupa Hasundau dalam membina karakter peserta didik di SDN 5 Menteng Palangka Raya dilakukan 2 kali pertemuan per semester, yaitu dilaksanakan pada awal semester dan pertengahan semester. Selanjutnya sekolah menyepakati untuk dilaksanakan pertemuan dengan orang tua siswa melalui undangan yang disebarkan melalui pesan pada grup WA atau surat. Teknis dari pertemuan tersebut sebagai wadah untuk berdiskusi antara pihak sekolah dengan orang tua siswa untuk menyampaikan pendapat ataupun kebutuhan yang diperlukan anak di sekolah, permasalahan yang dihadapi anak, pola asuh, serta memberikan materi yang bermanfaat untuk mendidik anak.

3. Faktor pendukung dan kendala yang dihadapi pada implementasi hasupa hasundau dalam membina peserta didik di SDN 5 Menteng Palangka Raya, sebagai berikut : (a) Faktor Pendukung: (1) Faktor pendukung kegiatan pertemuan antara pihak sekolah yang melibatkan orang tua siswa untuk kerja sama sehingga memberikan teladan dan menumbuhkan karakter peserta didik, (2) Adanya keterbukaan atau kepercayaan orang tua terhadap sekolah begitu sebaliknya dalam mendidik anak, kesamaan pola asuh, dan (3) Guru dan orang tua menjadi pro aktif dalam menyampaikan pendapat dan memantau perkembangan anaknya di sekolah atau di rumah; (b) Faktor Kendala: (1) Masih terdapat sebagian kecil orang tua yang kurang perduli akan pentingnya kegiatan pertemuan di Hasupa Hasundau, sehingga orang tua tidak mengetahui mengenai perkembangan anaknya di sekolah, dan (2) Pada saat pelaksanaan pertemuan ada beberapa orang tua yang berhalangan hadir karena masalah waktu, seperti orang tua yang sibuk bekerja.

\section{UCAPAN TERIMA KASIH}

Terima kasih yang sebesar-besarnya diucapkan kepada dosen pembimbing pertama dan kedua yang dengan kesabaran hati telah membimbing serta mengarahkan penulis dalam menyelesaikan karya ilmiah ini. Terima kasih juga diucapkan bagi Dekan Fakultas Keguruan dan Ilmu Pendidikan (FKIP) Universitas Palangka Raya dan Kepala SDN 5 Menteng Kota Palangka Raya yang telah memberikan ijin bagi penulis untuk melaksanakan penelitian, serta pihak Redaksi Equity in Education Journal (EEJ) yang telah memberikan kesempatan artikel saya dapat dimuat dalam jurnal ini.

\section{DAFTAR PUSTAKA}

Burhanuddin., Imron. A., Maisyaroh, Sutopo, H., Supriyanto, A., Bafadal, I., Setyadin, B., Effendi, A.R., Sahertian, P.A., \& Sultoni. (2003). Manajemen Pendidikan; Analisis Substantif dan Aplikasinya dalam Institusi Pendidikan (Imron, A., Burhanuddin, \& Maisyaroh, Ed). Malang: Universitas Negeri Malang. 
Departemen Pendidikan Nasional Direktorat Jenderal Pendidikan Dasar dan Menengah Direktorat Sekolah Lanjutan Tingkat Pertama. (2002). Jakarta.

FKIP. (2017). Buku Pedoman Penulisan Skripsi. Universitas Palangka Raya.

Iper, D. (2009). Kosakata Bahasa Dayak Ngaju-Indonesia. Palangka Raya. CV Anugerah Indah Mandiri.

Keith., \& Girling. (1991). Partisipasi Masyarakat, (Online), (http://www.google.com/url?sa=t $\& \mathrm{rct}=\mathrm{j} \& \mathrm{q}=\&$ esrc $=\mathrm{s} \&$ source $=$ web $\& \mathrm{~cd}=12 \& \mathrm{cad}=\mathrm{rja} \& u a c t=8 \& \mathrm{ved}=0$ CCAQFjABOAo\&url $=\mathrm{http} \% 3 \mathrm{~A} \%$ 2F\%2Frepository.upi.edu\%2F829 \%2F5\%2FT_ADPEN_009705_C

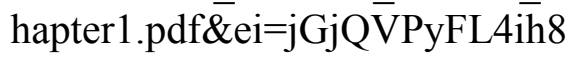
QWStoGACg\&usg=AFQjCNFGp r3mbrbtgR2mh3CfP8u5rz0ysw\& bvm=bv.85076809,d.dGc), diakses 3 Februari 2019.

Komariah, A., \& Triatna, C. (2008). Visionary Leadership menuju Sekolah Efektif. Jakarta : PT. Bumi Aksara.

Manap, S. (2013). Identifikasi Potensi Partisipasi Masyarakat dalam Peningkatan Sarana Pembelajaran di SMPN 1 Sindang Kelingi Kabupaten Rejang Lebong, Laporan Penelitian Penguatan Pembelajaran Program Magister Manajemen Pendidikan, Fakultas Keguruan dan Ilmu Pendidikan, Universitas Bengkulu, (Online), (http://www.google.com/url?sa=t $\& \mathrm{rct}=\mathrm{j} \& \mathrm{q}=\&$ esrc $=\mathrm{s} \&$ source $=\mathrm{web}$ $\& c d=16 \&$ cad $=$ rja\&uact $=8 \&$ ved $=0$ CDkQFjAFOAo\&url $=\mathrm{http} \% 3 \mathrm{~A} \%$ 2F\%2Frepository.unib.ac.id $\% 2 \mathrm{~F} 8$ 057\%2F1\%2FB6\%2520Manap \% 2C\%25202013\%2520\%2520PEN ELITIAN\%2520IDENTIFIKASI $\% 2520$ POTENSI\%2520PARTISI PASI\%2520MASYARAKAT.pdf \&ei=D0rPVISLA4PAmAXHz4C
oBg\&usg=AFQjCNFCP0SKBHK WPAgQ24mksqNeJkmWeA\&bv $\mathrm{m}=$ bv.85076809,d.dGY), diakses 2 Februari 2019.

Moleong, L. J. (2012). Metode Penelitian Kualitatif (edisi revisi). Bandung. PT Remaja Rosdakarya.

Mulyasa, E. (2013). Manajemen \& Kepemimpinan Kepala Sekolah. Jakarta: PT Bumi Aksara.

Peraturan Menteri Pendidikan dan Kebudayaan (Permendikbud) Nomor: 75 Tahun 2016 tentang Komite Sekolah.

Peraturan Menteri Pendidikan dan Kebudayaan Nomor 11 Tahun 2015 tentang Organisasi dan Tata Kerja Kementerian Pendidikan dan Kebudayaan.

Pidarta, M. (2011). Manajemen Pendidikan Indonesia. Jakarta: Rineka Cipta.

Roadmap Pendidikan Keluarga. (2015). Direktorat Pembinaan Pendidikan Keluarga, Direktorat Jenderal Pendidikan Anak Usia Dini dan Pendidikan Masyarakat, Kementerian Pendidikan dan Kebudayaan.

Suadin. (2017). Materi umum Kemitraan Sekolah dengan Keluarga dan Masyarakat. Diunduh pada tanggal 22 Oktober 2018. https://suaidinmath.files.wordpres s.com

Sugiyono. (2015). Metode Penelitian Pendidikan (Pendekatan Kuantitatif, Kualitatif, dan $R \& D$. Bandung: Alfabeta.

Suharto, T. (2012). Pendidikan Berbasis Masyarakat: Relasi Negara dan Masyarakat dalam Pendidikan. Yogyakarta: LKiS Yogyakarta.

Undang - Undang Sistem Pendidikan Nasional Nomor 20 Tahun 2003 Pasal 7.

Undang-Undang Pendidikan Nasional Nomor 20 Tahun 2003, BAB XV Pasal 54 ayat 1 tentang Peran Serta Masyarakat Dalam Pendidikan. 
Equity in Education Journal (EEJ), Vol. 1, No. 1, Oktober 2019

Undang-Undang Republik Indonesia Nomor 20 Tahun 2003 tentang Sistem Pendidikan Nasional.

Wahyuni, R. (2015). Manajemen Partisipasi Masyarakat dalam Pengambilan Keputusan dan Pengembangan Sekolah (Studi Multikasus pada SMA Negeri 4 dan SMA Katolik Santo Petrus Kanisius Kota Palangka Raya, Kalimantan Tengah), (Online), (http://karya-

ilmiah.um.ac.id/index.php/disertas i/article/view/38505), diakses 20 Oktober 2019. 